\title{
Rapid spread of the novel respiratory syncytial virus A ON1 genotype, central Italy, 2011 to 2013
}

\author{
A Pierangeli (alessandra.pierangeli@uniroma1.it) ${ }^{1}$, D Trotta $^{2}$, C Scagnolari ${ }^{1}$, M L Ferreri² $^{2}$ A Nicolai ${ }^{3}$, F Midulla ${ }^{3}$, K Marinelli², \\ G Antonelli ${ }^{1}$, P Bagnarelli ${ }^{2}$ \\ 1. Virology Laboratory, Department of Molecular Medicine, Sapienza University, Rome, Italy \\ 2. Department of Biomedical Sciences and Public Health, Virology Unit, Università Politecnica Marche, Ancona, Italy \\ 3. Department of Paediatrics, Sapienza University, Rome, Italy
}

Pierangeli A, Trotta D, Scagnolari C, Ferreri ML, Nicolai A, Midulla F, Marinelli K, Antonelli G, Bagnarelli P. Rapid spread of the novel respiratory syncytial virus A ON1 genotype, central Italy, 2011 to 2013 . Euro Surveill. 2014;19(26):pii=20843. Available online: http://www.eurosurveillance.org/ViewArticle.aspx?Articleld=20843

Article submitted on 30 August 2013 / published on 03 July 2014

Respiratory infections positive for human respiratory syncytial virus (RSV) subtype A were characterised in children admitted to hospitals in Rome and Ancona (Italy) over the last three epidemic seasons. Different strains of the novel RSV-A genotype ON1, first identified in Ontario (Canada) in December 2010, were detected for the first time in Italy in the following 2011/12 epidemic season. They bear an insertion of 24 amino acids in the $\mathbf{G}$ glycoprotein as well as amino acid changes likely to change antigenicity. By early 2013, ON1 strains had spread so efficiently that they had nearly replaced other RSV-A strains. Notably, the RSV peak in the 2012/13 epidemic season occurred earlier and, compared with the previous two seasons, influenza-like illnesses diagnoses were more frequent in younger children; bronchiolitis cases had a less severe clinical course. Nonetheless, the ON1-associated intensive care unit admission rate was similar, if not greater, than that attributable to other RSV-A strains. Improving RSV surveillance would allow timely understanding of the epidemiological and clinicopathological features of the novel RSV-A genotype.

\section{Introduction}

Human respiratory syncytial virus (RSV) is a major cause of lower respiratory-tract infection (especially bronchiolitis) in infants, but also affects immunocompromised and elderly patients [1]. In a small proportion of infected infants, severe RSV disease is characterised by wheezing, hyperinflation, atelectasis, increased mucus secretion, tachypnoea, retraction and consolidation. RSV, a Pneumovirus of the Paramyxoviridae family, has an enveloped, non-segmented, single-stranded, negative-sense RNA genome of approximately $15,000 \mathrm{nt}$, coding for 11 genes. It has been further divided into subtypes $A$ and $B$ [2] based on reactions with monoclonal antibodies against the glycoproteins $\mathrm{G}$ and $\mathrm{F}$. The attachment glycoprotein $\mathrm{G}$ is a transmembrane glycoprotein with an extracellular domain that consists of two hypervariable regions separated by a central conserved region spanning amino acids 151-190, comprising the receptor binding site [3].
Although the amino acid sequence of the hypervariable region can vary widely between subgroups and even among isolates, its amino acid content is reminiscent of mucin proteins [3]. These mucin-like domains present different $\mathrm{N}$ - and $\mathrm{O}$-linked glycosylation sites which may affect antigenicity [3]. Indeed, $G$ is the major antigenic protein of RSV; besides exhibiting marked genetic variability in the amino acid sequence, position and number of glycosylation sites, it may also differ in length due to insertions and mutations in premature stop codons [3]. The main genetic change detected to date is a 60 nt insertion in $\mathrm{G}$ (generating a 20 aa insertion in the C-terminal domain) in RSV-B strain BA [4].

Based on the genetic diversity of glycoprotein G, RSV-A has been classified into genotypes $\mathrm{GA}_{1}-\mathrm{GA}_{7}$, $\mathrm{SAA}_{1}$ and, recently, NA1-NA2 [5-7], and RSV-B into $\mathrm{GB}_{1}-\mathrm{GB}_{12}, \mathrm{SAB}_{1}-\mathrm{SAB}_{3}$ and $\mathrm{BA}$ [4-6]. Most molecular epidemiological studies have analysed the $G$ gene's hypervariable C-terminal domain; importantly, sequencing of the entire RSV genome of several circulating strains [8] confirmed that the evolutionary patterns and clades seen in the C-terminal part of the $G$ gene reflect those of the whole genome. Phylogenetic analysis documented that several C-terminal positions are positively selected hypervariable sites that may contribute to immune escape, promoting re-infection and recurrent circulation of a genotype $[9,10]$. Multiple genotypes can co-circulate during successive epidemic seasons, but a new subtype, or one spreading from different countries, may replace dominant strains $[7,8,11]$. Genotype BA spread slowly and sequentially worldwide [12], but over several years, a divergent BA lineage replaced all RSV-B genotypes [13,14].

Aside from the epidemiological impact, novel variants may display enhanced clinical severity with increased replication in the lower respiratory tract and/or hyperresponsiveness of the airways $[1,15]$, underlining the importance of monitoring their spread. 
In Italy there is no ongoing national surveillance for circulating RSV, and only one study has investigated the genetic diversity of RSV-A in different seasons, up to 2006 [16]. In that and in other European studies [12,17], phylogenetic analysis disclosed co-circulation of genotypes GA2 and GA5 from 1998 to 2006/07; GA7 was less common.

Within the framework of an ongoing study of paediatric respiratory infections, we genotyped RSV-positive cases detected in Rome and Ancona, central Italy, in the 2011/12 epidemic season. Unexpectedly, we detected $\mathrm{ON}_{1}$, the new RSV-A variant of GA2 genotype identified in Ontario (Canada) in 2010 [18]. ON1 bears a $72 \mathrm{nt}$ insertion in the $\mathrm{G}$ hypervariable region, corresponding to 24 aa (of which 23 are duplicated), the largest $\mathrm{G}$ protein genetic modification ever reported [18]. The ability of the $G$ protein to host long inserts without impairing function is due to the relatively loose structural constraints of the mucin-like domain, which determines rapid evolutionary changes and contributes to the pathogenicity of RSV and other negativestranded RNA viruses encoding this domain [19].

In this study, phylogenetic analysis of the $G$ gene of RSV-A strains circulating in the 2010/11, 2011/12 and 2012/13 epidemic seasons demonstrated the presence of ON1 genotype in the 2011/12 winter and its rapid spread in the following year. Investigating the spread of $\mathrm{ON}_{1}$ is important to understand the extent to which genetic variability can modify the epidemic behaviour of RSV at population level. Moreover, since antigenic variation may influence clinical outcomes, we also addressed the clinical impact of genotype $\mathrm{ON} 1$. Analysis of case distribution and clinical patient data showed differences between infections with $\mathrm{ON}_{1}$ genotype and those with previously circulating RSV-A strains.

\section{Methods}

\section{Patients and samples}

The study involved RSV-positive respiratory samples collected in the 2010/11, 2011/12 and 2012/13 epidemic seasons from two sets of patients: children presenting to the paediatric emergency department who were admitted for respiratory conditions and then diagnosed at the virology laboratory of the teaching hospital Policlinico Umberto I-Sapienza University of Rome (RM samples), and children admitted to the paediatric department of Azienda Ospedaliero-Universitaria Ospedali Riuniti di Ancona-Università Politecnica delle Marche, or to other paediatric departments of the Marche region that use the Ancona virology unit (AN samples). The two cities lie about $200 \mathrm{~km}$ apart in central Italy.

Informed consent was sought from the children's parents for participation in the study which had been approved by the ethics committee of the two hospitals.
Demographic and clinical data were taken from the medical files. A nine-point (o-8) clinical severity score based on (age-adjusted) respiratory rate, arterial oxygen saturation in room air, retraction and oral feeding ability were determined on admission [20].

\section{RSV detection}

Each institution used their own protocol to test upper respiratory tract samples for respiratory viruses as detailed below. Bronchoalveolar lavage (BAL) samples were taken from patients admitted to a paediatric intensive care unit (PICU) for severe respiratory conditions. In Rome, nasal washings and/or BAL were tested for 14 respiratory viruses with PCR-based tests, as described previously [20,21]. In Ancona, nasal swabs and/or BAL were first tested for RSV RNA using an in-house one-step multiplex real-time RT-PCR followed by further analyses with the Seeplex RV 15 ACE Detection Kit (Seegene, Korea) in RSV-negative samples. Information on PCR primers and probes is available from the authors on request.

\section{RSV-A sequencing}

About half of the RSV-A-positive samples were randomly selected for genomic characterisation. Amplicons (502 bp) for sequencing were obtained from RSV-A-positive samples with the A-Fseq (G gene position $481-498$ of the RSV-A2 reference strain) and the $F_{1}$ reverse primer targeting the fusion protein gene's 5 ' end [5]. Experimental details are available from the authors on request.

\section{Phylogenetic analysis}

The nucleotide sequences of a fragment of the second hypervariable region of the $\mathrm{G}$ gene (396 nt, corresponding to codon positions 167-298) from RSV-A isolates were determined and compared with reference strains in GenBank.

Sequences were edited using Bioedit v7.1.3 and aligned with reference sequences using CLUSTAL W. We analysed evolutionary relationships between the study sequences, and sequences recently circulating in the United States [8], Canada [18], Belgium [22], Japan [7] and Malaysia [23] together with reference strains representative of all RSV-A genotypes. The best-fit evolutionary model and parameters were selected using jModeltest vo.1.1 [24]. The general time reversible $+G(G T R+G)$ model of nucleotide substitution was the most appropriate for the dataset. The evolutionary parameters corresponding to the best-fit model were run in MEGA5 V5.2.1 [25] to obtain the distance matrix among groups, the tree topology under a strict maximum likelihood (ML) approach, and the significance of the tree topology by bootstrapping (1,000 replicates); the $p$-distance among sequence clusters was calculated by pairwise comparison including transitions and transversions.

Sequences were submitted to GenBank and assigned the following accession numbers: KC $858158-K C 858194$ 
and KC858195-KC858198 (AN and RM sequences; 2010/11); JX988439-JX988449, JX988453-JX988486 and JX988450-JX988452, JX988487-JX988499 (AN and RM sequences with/without the 24 aa insertion; 2011/12); KC858199-KC858245 and KC858246KC858257 (AN and RM sequences; 2012/13).

\section{Statistical analysis}

The Mann-Whitney U test was used to compare median patient age, Fisher's exact test to analyse independent categorical variables and the unpaired t-test to compare genetic distance group means. A p value of $<0.05$ was considered significant. SPSS (v17.0) was used for data analysis.

\section{Results}

\section{RSV-positive patients}

From November 2010 to May 2013, 515 RSV-positive patients were detected: 165 in Rome (mean age: 4.8 months; median age: 2.75 months; range: 0.2-29 months) and 350 in Ancona (mean age: 12.8 months; median age: 3 months; range: $0.1-163$ months). Their distribution is reported in Table $1: 180$ cases in 2010/11 (83 RSV-A, 97 RSV-B), 65 cases in 2011/12 (119 RSVA, 46 RSV-B) and 170 cases in 2012/13 (158 RSV-A, 12 RSV-B). All patients were hospitalised for respiratory conditions.

Of the 360 RSV-A positive samples, 161 were successfully sequenced and categorised in relation to the presence of a $72 \mathrm{nt}$ insert in the G gene (Table 2).

\section{RSV case distribution}

Analysis by week of presentation highlighted a different case distribution in the last season both in Rome and Ancona (Figure 1). In 2010/11 and 2011/12, the earliest RSV-associated hospitalisations occurred in mid-December (slightly earlier in Rome) and peaked in January and February; in 2012/13, the cases started in late November, with a larger number in both cities occurring earlier than in the previous two seasons, and peaking in week 51 (2012) and week 1 (2013) in Rome and Ancona, respectively. In 2012/13, RSV-A accounted for $93 \%$ of all cases.

\section{TABLE 1}

Number of respiratory syncytial virus-positive patients diagnosed at two institutions in Ancona and Rome during three epidemic seasons, Italy, November 2010-May 2013 $(\mathrm{n}=515)$

\begin{tabular}{|l|c|c|c|c|c|}
\hline \multirow{2}{*}{$\begin{array}{l}\text { Winter } \\
\text { seasons }\end{array}$} & \multicolumn{2}{|c|}{$\begin{array}{c}\text { RSV-A cases } \\
n=360\end{array}$} & \multicolumn{2}{c|}{$\begin{array}{c}\text { RSV-B cases } \\
n=155\end{array}$} & \multirow{2}{*}{$\begin{array}{c}\text { All } \\
\mathbf{n = 5 1 5}\end{array}$} \\
\cline { 2 - 5 } & Ancona & Rome & Ancona & Rome & \\
\hline $2010 / 11$ & 53 & 30 & 73 & 24 & $\mathbf{1 8 0}$ \\
\hline $2011 / 12$ & 79 & 40 & 34 & 12 & $\mathbf{1 6 5}$ \\
\hline $2012 / 13$ & 103 & 55 & 8 & 4 & $\mathbf{1 7 0}$ \\
\hline
\end{tabular}

RSV: respiratory syncytial virus.
TABLE 2

Sequence features of respiratory syncytial virus-A-positive strains in relation to the presence of a $72 \mathrm{nt}$ insert, Italy, November 2010-May 2013 ( $\mathrm{n}=161)$

\begin{tabular}{|l|c|c|c|c|c|}
\hline \multirow{2}{*}{$\begin{array}{l}\text { Winter } \\
\text { seasons }\end{array}$} & \multicolumn{2}{|c|}{$\begin{array}{c}\text { Non-ON1 } \\
n=95\end{array}$} & \multicolumn{2}{c|}{$\begin{array}{c}\text { ON1 } \\
n=66\end{array}$} & $\begin{array}{c}\text { All } \\
n=161\end{array}$ \\
\cline { 2 - 6 } & Ancona & Rome & Ancona & Rome & \\
\hline $2010 / 11$ & 37 & 4 & 0 & 0 & 41 \\
\hline $2011 / 12$ & 34 & 13 & 11 & 3 & 61 \\
\hline $2012 / 13$ & 7 & 0 & 40 & 12 & 59 \\
\hline
\end{tabular}

RSV: respiratory syncytial virus.

a RSV-A genotype without the insertion.

${ }^{b}$ RSV-A genotype with the insertion.

\section{ON1 detection}

Phylogenetic reconstruction of 85 unique sequences is reported in Figure 2. All AN and RM strains were derived from genotype $\mathrm{GA}_{2}$ and belonged to the recently described NA1 group $[7,23]$. They clustered into several distinct clades which, despite non-significant bootstrap values, reflect RSV-A variability and evolution during the three epidemic seasons. The major finding was that $51 \mathrm{AN}$ and 15 RM strains grouped with the novel genotype $\mathrm{ON}_{1}$ (ON67-1210A) [18], which is characterised by a $72 \mathrm{nt}$ insertion in $\mathrm{G}$, resulting in 24 extra amino acids of which 23 are duplications of aa 261-283. ON1 was not detected in Ancona or Rome in the $2010 / 11$ season; it accounted for 14 of $61(22.9 \%)$ strains sequenced in $2011 / 12$ and for 52 of 59 (88.1\%) strains analysed in $2012 / 13$. In that last season. it was the prevalent genotype in Ancona (40 ON1/47 RSV-A) and apparently the sole genotype in Rome (12/12).

\section{Sequence analysis}

The phylogenetic tree based on $G$ gene sequences (Figure 2) shows, next to the main branches, the amino acid substitutions identifying a subtree. At the nucleotide level, the mean p-distance among the 95 strains without the insertion (GA2; NA1 group) was greater than the one among the 66 strains bearing it (ON1), i.e. $0.022 \pm 0.016$ vs $0.012 \pm 0.009$ (mean \pm standard deviation, p<0.0001, unpaired t-test), suggesting a more recent common origin of the $\mathrm{ON}_{1}$ strains. As expected in this highly variable region, pairwise distances were higher at the amino acid than at the nucleotide level, and were $0.043 \pm 0.030$ and $0.028 \pm 0.022$ among strains without and with the insert, respectively ( $p<0.0001$, unpaired t-test). The alignment of deduced amino acid sequences is presented in Figure 3, with grey areas representing potential $\mathrm{N}$-glycosylation sites.

Overall our strains presented very few amino acid substitutions in the conserved central portion (up to aa 198) of the G protein, whereas, as expected, several variations with respect to the reference $\mathrm{GA}_{2}$ sequence were found in the hypervariable portion. 
Respiratory syncytial virus cases, distribution of hospitalised children, Italy, November 2010-May 2013 (n=515)
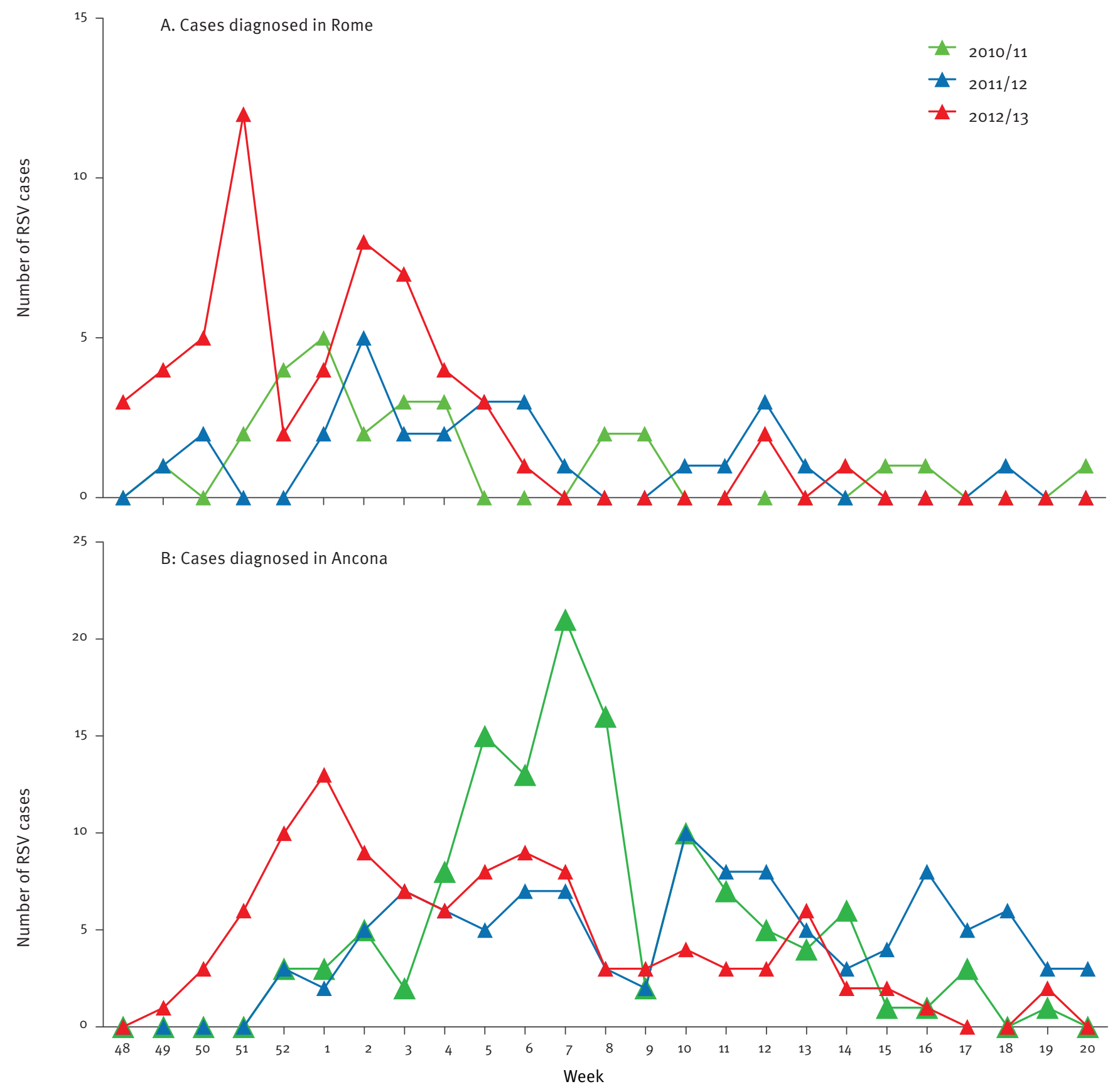

RSV: respiratory syncytial virus.

Results are weekly data for each epidemic season.

All study sequences clearly differed from the reference GA2 genotype, as demonstrated by the R204K, L215P, S230P conserved substitutions, also found in recently circulating strains of GA2 group, i.e. the NA1, NA2 and ON1 genotypes. Importantly, amino acid positions 215 and 230 are highly variable, positively selected sites [10]. Moreover, all study strains bore the N297K substitution and all but one (17294AN, detected in 2011/12) also exhibited substitution P292S, another positively selected site [10]. Most AN and RM sequences bore the
P274L substitution (a positively selected site) that had been detected in NA1 variants in Belgium, Wisconsin, Japan and Malaysia, but not in nine 2010/11 and in one 2011/12 sequences analysed in this study. The substitutions /208L and N273Y/H/D were also found. Changes at position 273 are particularly interesting as they involve the loss of a potential glycosylation site; they occurred in 18 strains from 2010/11), 23 strains from 2011/12 and six strains from 2012/13. 
The $\mathrm{N} 273 \mathrm{Y}$ substitution was also conserved in the welldefined clade containing 14 (2011/12) and $53(2012 / 13)$ study strains with $\mathrm{ON}_{1}$ genotype $(\mathrm{ON} 67-1210 \mathrm{~A})$. This cluster displayed the characteristic 72 nt duplication and three amino acid variations E232G, T253K and $\mathrm{P} 290 \mathrm{~L}$, the latter a reversal mutation compared with all other study sequences. Importantly, T253K is related to the loss of another potential $\mathrm{N}$-glycosylation site besides that determined by N273Y; the loss of two potential $\mathrm{N}$-glycosylation sites is a major characteristic of strain ON67-1210A [18]. Moreover our ON1 strains presented several amino acid substitutions in the hypervariable portion of the $\mathrm{G}$ protein and in the 24 aa insert compared with the ON1 prototype (Figure 3). When amino acid sequences of the duplicated tract were compared with the homologous 23 aa portions (aa 261-283), variations from the ON1 prototype were generally found either in the insertion or in its homologous tract (Figure 3), suggesting that they arose after the insertion event. Interestingly, however, a reversion in the positively selected site 274 (L274P) was found in a single 2011/12 strain (12221AN) and in 35 of $52(67 \%)$ $2012 / 13$ strains (both AN and RM) in the insert or in the homologous 23 aa portion (L274P and/or LxvP), nearly always together with the $\mathrm{YxxiH}$ change in the insert.

\section{Patient data and clinical diagnosis}

Demographic and clinical data were available for 99 patients infected with RSV-A-positive strains sequenced in 2011/12 and 2012/13; data stratified by RSV strain are reported in Table 3.

Overall, children whose RSV strain bore the insertion were significantly younger than those infected with the other strains, they had less frequently bronchopneumonia and more frequently influenza-like illness (ILI). $\mathrm{ON}_{1}$ infection caused more, although not statistically significant $(p=0.053)$, PICU admissions than the other RSV-A strains (Table 3 ).

We then evaluated 52 bronchiolitis patients for whom clinical data were exhaustive (Table 3); PICU cases were excluded due to insufficient clinical information and lack of an overall assessment of risk factors for severe RSV disease. Patients positive for an RSV-A strain that bore the insertion were less likely to have an elevated respiratory rate and exhibited a lower, although not statistically significant, clinical severity score (Table 3).

\section{Discussion}

It has been estimated that RSV infects $70 \%$ of children during their first year of life and that nearly all two yearolds have been infected; in addition, more than one third of children younger than two years get infected at least twice with RSV strains not only heterologous at the subtype level (i.e. RSV-A and RSV-B), but also homologous (i.e. RSV-A and RSV-A or RSV-B and RSVB) $[1,26]$. It is not entirely clear whether this is because RSV infection does not confer long-lasting protective immunity in humans, or because recurrent infections
FIGURE 2

Phylogenetic tree based on the second hypervariable region of the $G$ protein gene, Italy November 2010-May 2013 ( $\mathrm{n}=85$ unique Italian sequences, $\mathrm{n}=16$ reference strains)

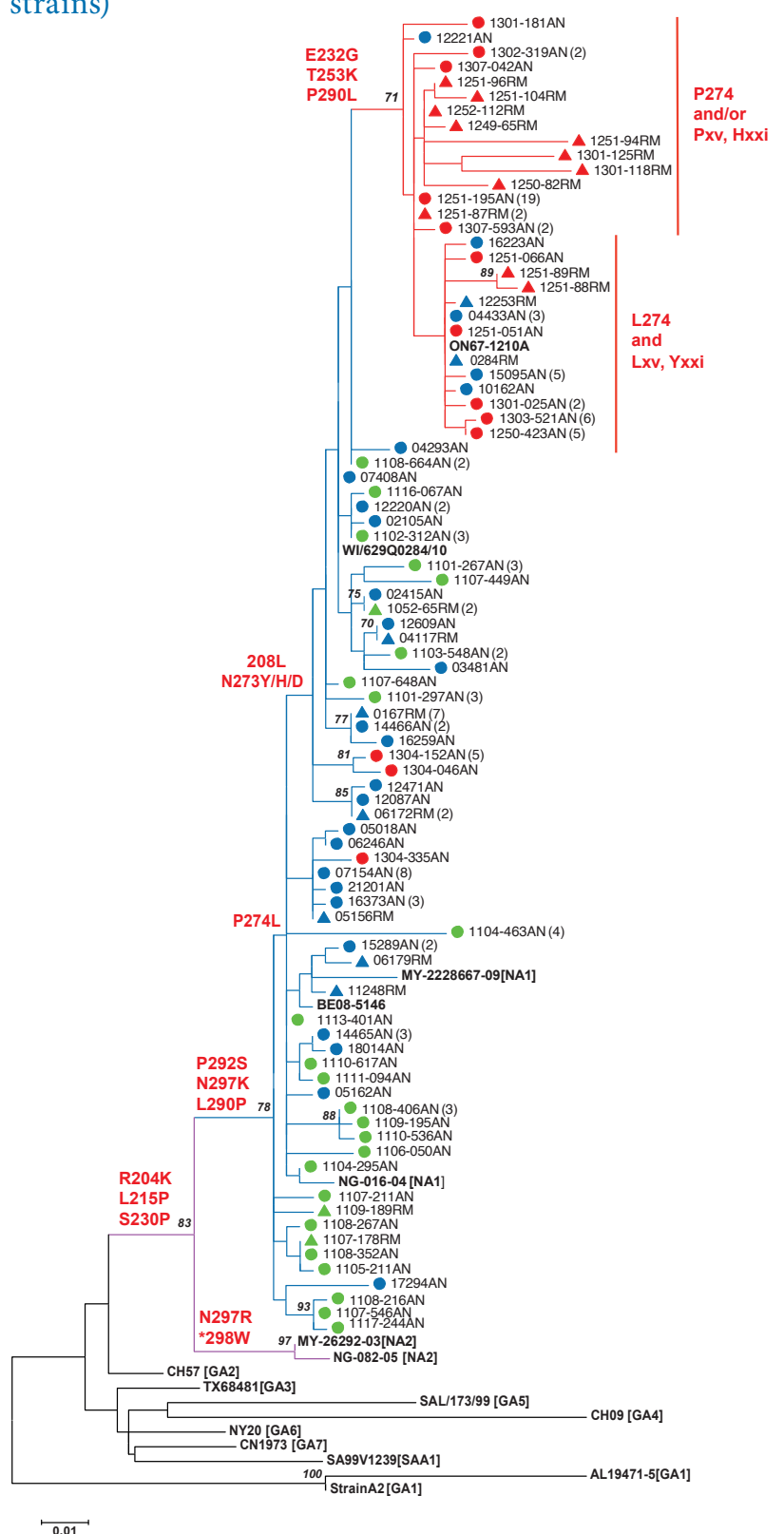

The best-fit evolutionary model and the parameters selected by the jModeltest programme were used as described in the text. The scale bar shows the proportions of nucleotide substitutions per site. Numbers at nodes are bootstrap values for 1,000 iterations; only bootstrap values of $>70 \%$ are shown. Numbers in round brackets indicate the total number of strains with an identical the RSV-A reference sequence.

Branches are colour-coded according to the deduced amino acid sequence, identifying subtrees and genotypes: red: sequences with insertion clustering with the novel ON1 genotype; blue sequences of NA1 genotype clustering with sequences from the United States (Wisconsin) [8], Europe (Belgium) [22] Malaysia (Kuala Lampur) [23] and Japan (Niigata City) [7]; purple: sequences of NA2 genotype from Malaysia (Kuala Lampur) and Japan (Niigata City), added for clarity. Circles: strains isolated in Ancona; triangles: strains isolated in Rome. Symbol colour indicates epidemic season: green: 2010/11; blue: 2011/12; red: $2012 / 13$.

GenBank accession numbers of RSV strains (this study) are reported in the text; reference strain accession numbers are: ON67-1210A (JN257693), WI/629-Q0284/10 (JF920053), MY2228667-09 (JX256883), BE08-5146 (JX015499), NG-016-04 2228667-09 ( MB 25688778), MY-26292-03 (JX256960), NG-082-05 (AB470479), CH57 (AF065258), TX68481 (AF233920), SAL/173/99 (AY472094), CH57 (AF065258), TX68481 (AF233920), SAL/173/99 (AY4 472 SA99V1239 (AF348808), AL19471-5 (AF233902), strain A2 (M74568). 


\section{FIGURE 3}

Alignment of deduced G protein amino acid sequence of RSV-A strains isolated in Ancona and Rome, Italy, November 2010-May $2013(n=161)$

\begin{tabular}{|c|c|c|}
\hline $\begin{array}{l}\text { CH57 } \\
\text { BE08 } 5146\end{array}$ & $\begin{array}{l}\ldots|\ldots| \ldots|\ldots| \\
\text { VFNEVPCSICSNNPT } \\
\ldots \ldots \ldots \ldots \ldots \ldots\end{array}$ & 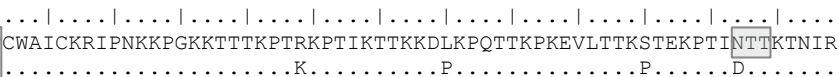 \\
\hline WI $/ 6 \overline{2} 900284 / 10$ & & 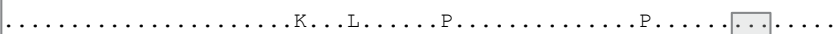 \\
\hline $\begin{array}{l}\text { NG-016-04-NA1 } \\
1108-352 \mathrm{AN}(2)^{\mathrm{a}}\end{array}$ & & $\begin{array}{l}\ldots \text { P. } \ldots \ldots \ldots \ldots \text { P. } \ldots \ldots \text { D. } \\
\ldots \text { P. } \ldots \ldots \ldots \ldots \text { P. }\end{array}$ \\
\hline $\begin{array}{l}1105-211 \mathrm{AN} \\
1108-267 \mathrm{AN}\end{array}$ & & 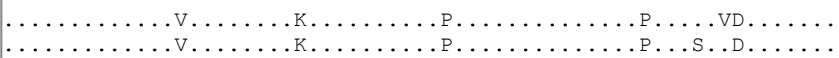 \\
\hline $\begin{array}{l}1107-211 \mathrm{AN} \\
1109-189 \mathrm{RM}\end{array}$ & & 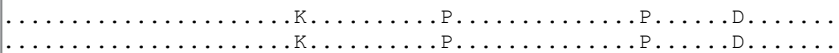 \\
\hline $1107-546 \mathrm{AN}(2)$ & $\cdots$ & 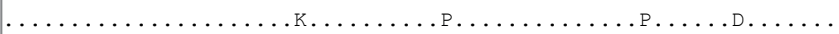 \\
\hline $\begin{array}{l}1108-216 \mathrm{AN} \\
17294 \mathrm{AN}\end{array}$ & & $\begin{array}{l}1 \\
12 \mathrm{R}\end{array}$ \\
\hline 12471AN & & $\ldots \ldots \ldots \ldots \ldots \ldots \ldots$ К. \\
\hline $1104-463 \mathrm{AN}(4)$ & & 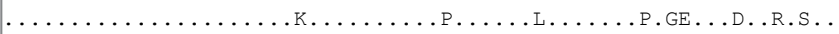 \\
\hline $16373 \mathrm{AN}(12)^{\mathrm{a}}$ & $\ldots \ldots \ldots$ & 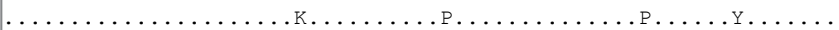 \\
\hline 1304-335AN & & $\ldots \ldots \ldots \ldots \ldots \ldots \ldots \ldots \ldots \ldots$ \\
\hline 05018AN (2) & & $\ldots P \ldots \ldots \ldots \ldots$ \\
\hline $1108-406 \mathrm{AN}(4)$ & $\ldots$ & $\ldots \ldots$. $\ldots \ldots \ldots \ldots$ Р. \\
\hline $1110-536 \mathrm{AN}$ & & 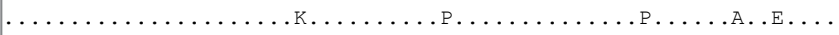 \\
\hline 1113-401AN (2) & & 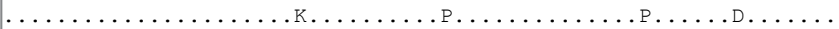 \\
\hline 05162AN & & 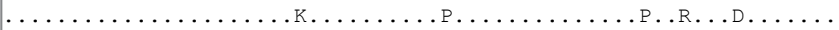 \\
\hline 1106-050AN & & .Р......... \\
\hline $14465 \mathrm{AN}(4)$ & $\ldots$ & 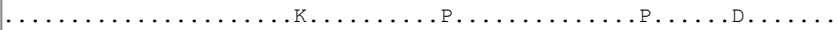 \\
\hline 18014AN & $\cdots$ & 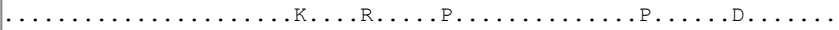 \\
\hline $1111-094 \mathrm{AN}$ & ... & \\
\hline 15289AN (2) & $\ldots \ldots \ldots$ & $\ldots \ldots \ldots$. $\ldots \ldots \ldots \ldots$. $\ldots$ \\
\hline $11248 \mathrm{RM}$ & & $\ldots \ldots \ldots$. $\ldots \ldots \ldots \ldots$. \\
\hline 06179RM & $\cdots$ & 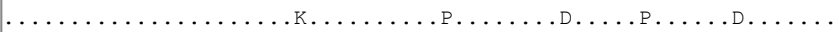 \\
\hline $14466 \mathrm{AN}(9)^{\mathrm{a}}$ & & $\ldots \ldots \ldots \ldots \ldots \ldots \ldots \ldots$ к. \\
\hline 16259AN & $x^{2}>$ & 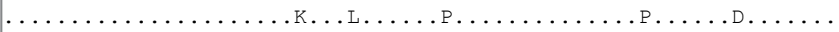 \\
\hline 1101-297AN (3) & ... & 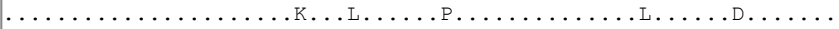 \\
\hline 1107 & &.$K \ldots \perp \ldots \ldots$. $\ldots \ldots \ldots \ldots \ldots$. \\
\hline 1304-152AN (5) & $\ldots$ & \\
\hline 1304-046AN & & 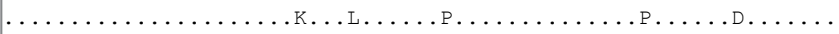 \\
\hline $12087 \mathrm{AN}(3)^{\mathrm{a}}$ & & 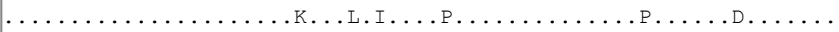 \\
\hline 04293AN & $\ldots$. & .K...L............. \\
\hline $1108-664 \mathrm{AN}(2)$ & &.$K \ldots \perp \ldots \ldots P \ldots \ldots \ldots$ \\
\hline 1101-267AN (3) & & 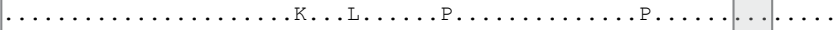 \\
\hline $\begin{array}{l}1107-449 \text { AN } \\
02415 \mathrm{AN}(3)^{\mathrm{b}}\end{array}$ & & 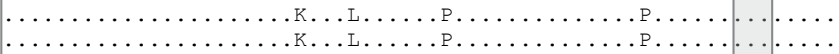 \\
\hline 12609AN (2) ${ }^{\mathrm{a}}$ & & 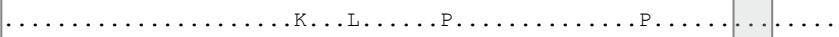 \\
\hline $1103-548 \mathrm{AN}(2)$ & & .K...L.... . . \\
\hline $03481 \mathrm{AN}$ & & $\ldots \ldots \ldots$ I. $\ldots \ldots \ldots$ К. \\
\hline $\begin{array}{l}\text { 02105AN } \\
1102-312 \mathrm{AN}(6)^{\mathrm{c}}\end{array}$ & & 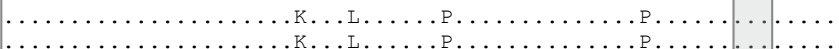 \\
\hline $1116-067 \mathrm{AN}$ & & 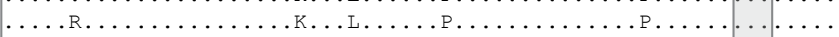 \\
\hline ON67-12 & VFNFVPCSIC & CWAICKRI PNKKPGKKTTTKPTKKPTLKTTKKDPKPQTTKPKEVLTTKPTGKPT \\
\hline $04433 \mathrm{AN}(5)^{\mathrm{d}}$ & .. & $\ldots \ldots \ldots \ldots \ldots \ldots \ldots$. \\
\hline $\begin{array}{l}\text { 1251-066AN } \\
12253 \mathrm{RM}(2)\end{array}$ & & 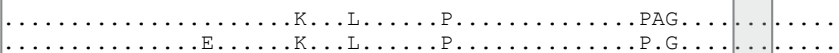 \\
\hline $10162 \mathrm{AN}$ & & $\ldots \ldots \ldots \ldots$. \\
\hline 16223AN & & .K...L. \\
\hline 15095AN (5) & $\ldots$ & 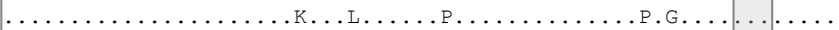 \\
\hline 1251 & $\ldots$... & .K...L. . \\
\hline 1251-89RM & & .P.G. \\
\hline 1303-521AN (11) & & .K...L. \\
\hline $1301-025 \mathrm{AN}(2)$ & & .K...L. \\
\hline 1251-94RM & $\ldots . . A$ & 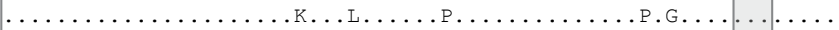 \\
\hline $12221 \mathrm{AN}$ & & .K...L. . \\
\hline $1251-195 \mathrm{AN}(21)^{\mathrm{a}}$. & & 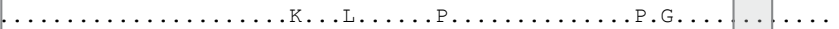 \\
\hline 1307-593AN (2) & & ......P.G. \\
\hline $042 \mathrm{AN}$ & & .P.G. \\
\hline 1302-319AN (2) & & .K.Q.L. \\
\hline 1251-96RM & & .P. \\
\hline $1251-104 \mathrm{RM}$ & ...... & 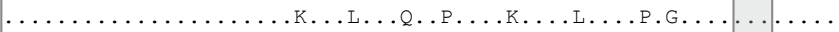 \\
\hline 1252-112RM (2) & ....... &.$K \ldots \perp \ldots \ldots P$. \\
\hline 1301-118RM & & . K...L. \\
\hline $1301-125 \mathrm{RM}$ & & .P.G.S. \\
\hline $1301-181 \mathrm{AN}$ & & ...... \\
\hline 1250-82RM & .A. & \\
\hline
\end{tabular}

a Strain observed in AN and RM.

b Strain observed in AN and RM, in 2010-11 and 2011/12.

' Strain observed in 2010/11 and 2011/12.

d Strain observed in AN and RM in 2011/12 and 2012/13.

Alignments of 65 unique sequences are shown relative to the sequence of the prototype $\mathrm{GA}_{2} \mathrm{CH}_{57}$ (AF065258) used as the reference strain Reference sequences belonging to the NA1 subgroup of the GA2 genotype circulating in Europe (BE08-5146, JX015499), the United States (WI/629-00284/10, JF920053) and Japan (NG-016-04, AB470478) are included for clarity. Amino acid numbering from 167 to 298 refers to the G glycoprotein of the reference strains without insertion, Roman numerals indicate the position in the amino acid insertion. The ON67-1210A (ON1 genotype, JN257693) sequence with the 24 aa insertion (23 of which are duplicated) is used as the prototype for the Italian strains with the insertion. Dots indicate nucleotides identical to the $\mathrm{CH}_{57}$ strain; the sequence of the ON1 prototype is shown only for clarity. Dashes indicate the gap corresponding to the nucleotide insertions, asterisks indicate stop codons. Black boxes indicate the duplicated region (homologous portion and insertion); sequences within the box are shown independently of identities to the ON1 prototype, mutations are shown in red and bold. Grey shading indicates potential N-glycosylation sites. Colour of sequence names indicates the epidemic season: green: 2010/11; blue: 2011/12; red: 2012/13. Numbers in parentheses indicate the total number of identical strains. 


\section{FIGURE 3}

Alignment of deduced G protein amino acid sequence of RSV-A strains isolated in Ancona and Rome, Italy, November 2010-May $2013(n=161)$

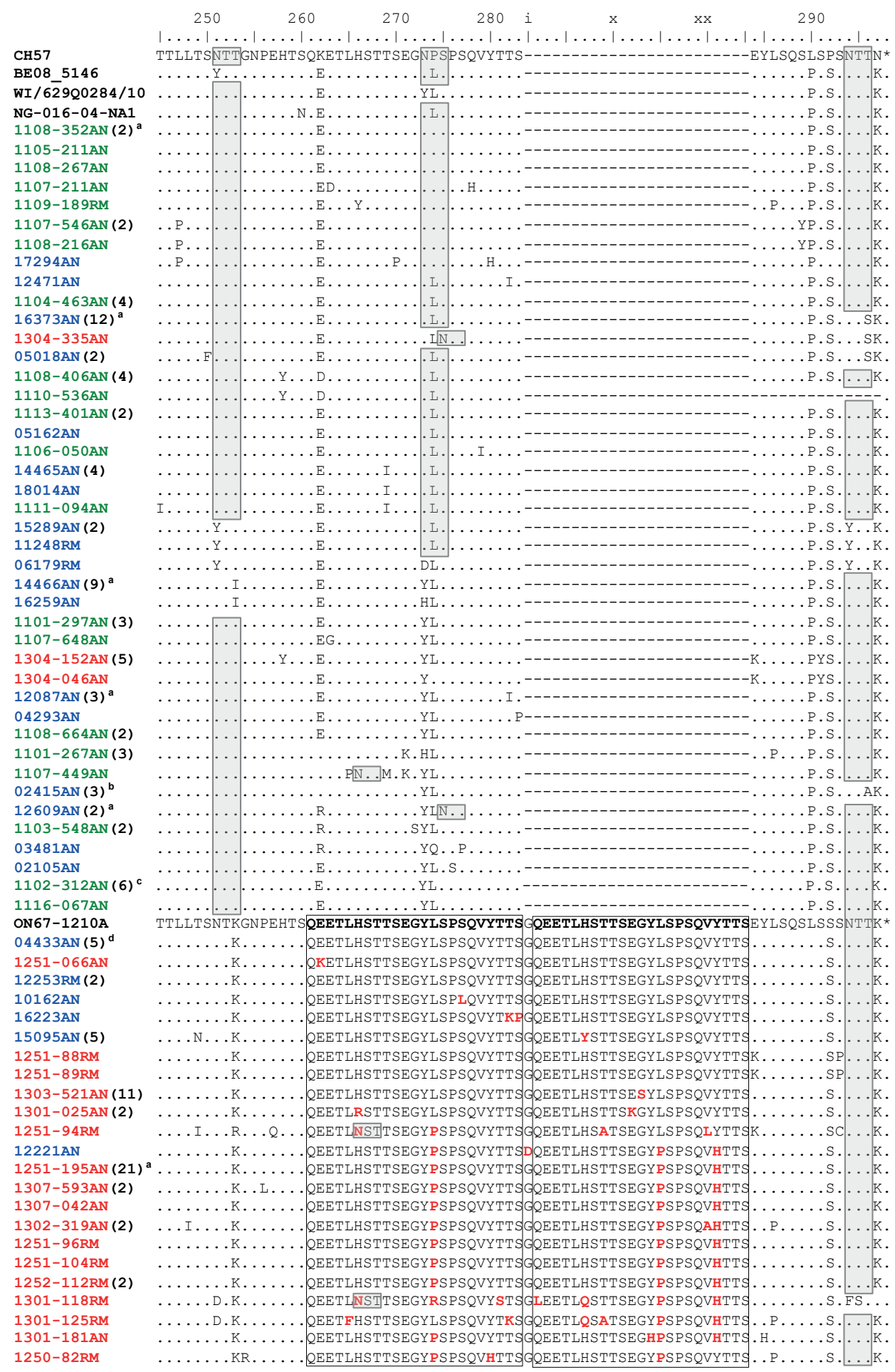

a Strain observed in AN and RM.

${ }^{b}$ Strain observed in AN and RM, in 2010-11 and 2011/12.

' Strain observed in 2010/11 and 2011/12.

d Strain observed in AN and RM in 2011/12 and 2012/13.

Alignments of 65 unique sequences are shown relative to the sequence of the prototype $\mathrm{GA}_{2} \mathrm{CH}_{57}$ (AF065258) used as the reference strain. Reference sequences belonging to the NA1 subgroup of the GA2 genotype circulating in Europe (BE08-5146, JX015499), the United States (WI/629-Q0284/10, JF920053) and Japan (NG-016-04, AB470478) are included for clarity. Amino acid numbering from 167 to 298 refers to the G glycoprotein of the reference strains without insertion, Roman numerals indicate the position in the amino acid insertion. The ON67-1210A (ON1 genotype, JN257693) sequence with the 24 aa insertion (23 of which are duplicated) is used as the prototype for the Italian strains with the insertion. Dots indicate nucleotides identical to the $\mathrm{CH}_{57}$ strain; the sequence of the ON1 prototype is shown only for clarity. Dashes indicate the gap corresponding to the nucleotide insertions, asterisks indicate stop codons. Black boxes indicate the duplicated region (homologous portion and insertion); sequences within the box are shown independently of identities to the ON1 prototype, mutations are shown in red and bold. Grey shading indicates potential N-glycosylation sites. Colour of sequence names indicates the epidemic season: green: 2010/11; blue: 2011/12; red: 2012/13. Numbers in parentheses indicate the total number of identical strains. 
even with the same subtype are due to significant antigenic changes in the immunodominant proteins $[1,26]$.

Emerging RSV variants that possess a selective advantage in terms of genetic diversity can spread to neighbouring areas, gradually replacing dominant genotypes over several years $[7,11,22]$. A well- studied example is a 20 aa insertion in the $G$ protein (comparable in length and position to the insertion in $\mathrm{ON}_{1}$ ) that arose in RSV-B BA strains; it was first detected in 1999 in Argentina [4] and spread worldwide in the course of several epidemic seasons [12-14,22]. In apparent contrast to its epidemiological success, a BA strain was efficiently neutralised by sera from patients previously infected with non-BA RSV-B [27]. However, homologous subgroup reinfections were reported with both RSV-A and RSV-B strains [26,28].

Our findings document the presence of the novel $\mathrm{ON}_{1}$ genotype in Italy in the 2011/12 epidemic season and its rapid spread in 2012/13. All other RSV-A G-gene variants described here derive from the GA2 genotype and are genetically close to the recently characterised NA1 genotype, as are most recent strains circulating worldwide $[18,23,28]$.

The ON1 genotype was first detected in Ontario in the winter of 2010/11 [18], then in 2011/12 season in South Africa [29], Malaysia [23] and Germany [30], with an infection rate of around $10 \%$ among hospitalised children. Compared with the near absence of $\mathrm{ON}_{1}$ infections in central Italy in $2010 / 11$, we here report a $23 \%$ rate in 2011/12 and, remarkably, a nearly $90 \%$ rate in $2012 / 13$, i.e. a nearly complete replacement of previously circulating RSV-A strains by the new genotype within just one year. This rapid diffusion of this strain was probably made possible by its genetic diversity in the $\mathrm{G}$ protein. Moreover, the $\mathrm{ON}_{1}$ study strains of the 2012/13 season displayed several amino acid substitutions compared with the $\mathrm{ON}_{1}$ prototype and with $\mathrm{ON}_{1}$ strains deposited in GenBank [18,23,30].

The variability and apparent evolution seen at the positively selected site 274 in the $\mathrm{ON}_{1}$ cluster of sequences is particularly interesting. All 2011/12 strains but one $(12221 \mathrm{AN})$ had a leucine in this position, like most

\section{TABLE 3}

Demographic and clinical data of respiratory syncytial virus-A-positive patients diagnosed during the 2011/12 and 2012/13 seasons, stratified by RSV-A genotype, Italy $(\mathrm{n}=99)$

\begin{tabular}{|c|c|c|c|c|}
\hline Features & $\begin{array}{l}\text { RSV-A } \\
n=99^{a}\end{array}$ & $\begin{array}{c}\text { Non-ON1 } \\
n=43\end{array}$ & $\begin{array}{c}\mathrm{ON}_{1} \\
\mathrm{n}=56\end{array}$ & $p$ value ${ }^{b}$ \\
\hline Median age, months (range) & $2.8(0.4-60)$ & $5.0(0.5-60)$ & $2.5(0.4-32)$ & 0.030 \\
\hline Patient younger than one year, n (\%) & $85(85.6)^{c}$ & $33(76.7)$ & $52(92.8)$ & 0.039 \\
\hline Male sex, n (\%) & $66(66.6)$ & $30(69.8)$ & $36(64 \cdot 3)$ & 0.66 \\
\hline \multicolumn{5}{|l|}{ Clinical diagnosis $^{d}$} \\
\hline Bronchiolitise $^{\mathrm{e}}$ n (\%) & $61(61.9)\{7\}$ & $26(60.5)\{1\}$ & $35(62.5)\{6\}$ & 0.838 \\
\hline Wheezing/asthma, n (\%) & $9(9.1)$ & $3(7.0)$ & $6(10.7)$ & 0.727 \\
\hline Bronchopneumonia, n (\%) & $16(16.2)\{4\}$ & $12(27.9)\{2\}$ & $4(7.1)\{2\}$ & 0.011 \\
\hline $\mathrm{ILI}^{\mathrm{f}}, \mathrm{n}(\%)$ & $13(13.1)\{1\}$ & $2(4.6)$ & $11(19.6)\{1\}$ & 0.036 \\
\hline PICU admission, $\mathrm{n}(\%)$ & $12(12.1)$ & $3(7.0)$ & $9(16.1)$ & 0.053 \\
\hline Bronchiolitis patients ${ }^{g}$ & $\begin{array}{c}\text { RSV-A } \\
n=52\end{array}$ & $\begin{array}{c}\text { Non-ON1 } \\
n=23\end{array}$ & $\begin{array}{c}\text { ON1 } \\
n=29\end{array}$ & \\
\hline Median age, months (range) & $2.0(0.3-9)$ & $2.5(0.3-8)$ & $1.6(0.5-9)$ & 0.110 \\
\hline Male sex, $\mathrm{n}(\%)$ & $35(67.3)$ & $15(65.2)$ & $20(69.0)$ & 1.000 \\
\hline O2 saturation $<95 \%, \mathrm{n}(\%)$ & $25(47.2)$ & $13(54.2)$ & $12(41.4)$ & 0.403 \\
\hline Retractions, n (\%) & $36(69.2)$ & $17(73.9)$ & $19(65 \cdot 5)$ & 0.560 \\
\hline Severity score $4-8^{\mathrm{h}}, \mathrm{n}(\%)$ & $13(25.0)$ & $9(39.1)$ & $4(13.8)$ & 0.053 \\
\hline
\end{tabular}

ILI: influenza-like-illness; PICU: paediatric intensive care unit; RSV: respiratory syncytial virus.

a Number of patients for whom data were available.

b Mann-Whitney test for the difference in median age; Fisher's exact test for analysis of independent categorical variables. Bold indicates a significant result.

In parentheses the proportion of cases with the condition among the total cases per group.

Clinical diagnosis on admission; number of PICU admissions in curly brackets.

Bronchiolitis was defined as a history of upper respiratory tract infection followed by acute onset of respiratory distress with cough, tachypnoea, retraction and diffuse crackles on auscultation in infants within one year [20].

ILI was defined according to the Italian Health Ministry as fever (temperature $\geq 38{ }^{\circ} \mathrm{C}$ ), with at least one of the following symptoms: headache, asthenia, myalgia, and at least one of the following respiratory symptoms: cough, rhinitis, acute pharyngitis.

g Clinical data were available for 52 of 61 patients admitted for bronchiolitis (excluding PICU cases).

h Clinical severity score $(0-8)$ including subscores for respiratory rate ( 45 breaths $/ \mathrm{min}=0,45-60 \mathrm{breaths} / \mathrm{min}=1,>60 \mathrm{breaths} / \mathrm{min}=2)$; arterial oxygen saturation in room air $(>95 \%=0,95-90 \%=1,<90 \%=2)$; presence of retractions (none $=0$, present $=1$, present + nasal flare $=2)$, and feeding ability (normal $=0$, reduced $=1$, intravenous $=2$ ) [20]. 
strains circulating then and in the previous winter as well as the $\mathrm{ON}_{1}$ prototype. The reversal mutation involving a proline at site 274 , first detected in the $12221 \mathrm{AN}$ strain in the homologous portion and in the insert (LxvP), together with the YxxiH substitution, seemed to confer an evolutionary advantage, being found in most (31/52 sequences; 60\%) 2012/13 strains. Notably, this variant was circulating during the 2011/12 winter as a minority strain also in Germany [30] and Japan (GenBank: AB698559). These variations may have arisen from independent evolutionary reversal events affecting the amino acid at site 274 and its homologous position in the insert, as may happen in those sites following the so called 'flip-flop' phylogenetic pattern (i.e. a frequently reversible amino acid replacement) [10]. Alternatively, the duplication event may have occurred independently in a strain already bearing the $L 274 \mathrm{P}$ substitution, generating the same substitution in its homologous position in the insert, followed by a second independent mutation at insert position $x x i$. ON1 strains with $274 \mathrm{P}$ and/or $x v P$ in the homologous and insert portion spread widely in the population, accounting for $67 \%$ of $2012 / 13$ strains.

Overall, a variety of genetic changes could be responsible for the spread of ON1 strains, conferring low crossprotection by pre-existing antibodies to RSV-A strains previously circulating in Italy: the 24 aa insertion, the loss of a further potential glycosylation site due to the T253K substitution, and even other amino acid changes. Unfortunately, we were not able to culture ON1 clinical isolates and could therefore not assess the antigenic properties of these strains.

Nonetheless, the ability to replace circulating RSV-A strains and the fact that the peak of RSV infections occurred earlier in $2012 / 13$ than in the previous two seasons, could be the consequence of broad antigenic diversity. Another possible consequence of antigenic diversity could be that newborns infected with a novel genotype would be less protected by maternal antibodies against previously circulating RSV-A strains. This would be consistent with our finding that hospitalised patients with $\mathrm{ON}_{1}$ were younger than those with other RSV strains, as was also seen in a German report for July 2010 to June 2012 [30]. In contrast, a Japanese study reported that patients infected with a novel GA2 variant, NA2, had a greater mean age than those infected with the previously circulating $\mathrm{GA}_{5}$ genotype [7]. The difference could be related to viral characteristics or, more probably, to the study population, since the Japanese study described cases reported to the national surveillance by sentinel paediatric clinics, whereas all our samples were from hospitalised children; we could therefore not assess the impact of the novel genotype at the population level.

Besides the epidemiological impact, significant genetic variation in circulating strains may involve different pathogenicity and virulence. Several publications have recently documented that different patient isolates are able to induce variable pathogenesis in a mouse model [31] and in cell culture [32]. Moreover, novel substitutions and deletions were identified in RSV strains from clinical samples of severely ill patients [15].

In this study we analysed demographic and clinical data from about 100 RSV cases and from 52 well-characterised bronchiolitis patients, and found differences between infections with $\mathrm{ON}_{1}$ vs $\mathrm{GA}_{2}$ strains. $\mathrm{ON}_{1}$ patients were significantly younger than those infected with the other RSV-A strains $(p=0.03)$; they were more frequently affected with less severe clinical conditions; bronchiolitis severity was lower, as documented by the significantly better respiratory condition $(p=0.043)$ and the considerably lower severity score $(p=0.053)$. A milder clinical course among children infected with genotype $\mathrm{ON}_{1}$ compared to infections with other RSV infections was recently reported in Cyprus [33]. On the other hand, PICU admissions were more numerous for ON1 than for the other RSV-A strains $(p=0.053)$, as also reported in the German study [30]. Given these contrasting observations, the novel genotype does not seem to possess special determinants of severity compared with previously circulating RSV-A strains, but its sudden diffusion due to genetic differences could have increased the epidemic peak, the number of hospitalised patients and consequently PICU admissions.

Undoubtedly, it is of interest to investigate viral and host pathogenic factors during both severe and mild RSV infection, but the challenge is to characterise RSV strains and clinical conditions from a sufficiently large number of patients to assess associations. In several European countries, weekly reports of influenza virus characterisation also contain RSV detection in ILI cases reported by sentinel primary care physicians, issued by the European Influenza Surveillance Network (EISN). In Italy, RSV testing of ILI samples was performed in the framework of the EISN RSV Task Group up to year 2007 [34].

The Task Group's report recommended improving RSV surveillance using molecular techniques yet to be standardised and setting up a sentinel system of representative hospitals to determine the burden of RSV illness and define its epidemiology [34]. Research projects would now be well timed to monitor the diffusion of the novel ON1 genotype and of the other RSV strains in the general population and to determine their hospitalisation rate and clinical impact. This knowledge could also help include the more virulent strains in vaccines.

Acknowledgements

This study was partly supported by grants from Sapienza University of Rome to CS.

Conflict of interest

None declared. 


\section{Authors' contributions}

AP and PB designed the study, had primary responsibility for analysis of the results and wrote the paper; DT conducted research in Ancona and performed phylogenetic analysis; CS conducted research in Rome; MLF and KM performed virological diagnosis and collected patient data in Ancona; AN and FM collected respiratory samples and patient data in Rome; $\mathrm{GA}$ analysed the results and contributed to writing the paper.

\section{References}

1. González PA, Bueno SM, Carre-o LI, Riedel CA, Kalergis AM. Respiratory syncytial virus infection and immunity. Rev Med Virol. 2012;22(4):230-44. http://dx.doi.org/10.1002/rmv.1704

2. Mufson MA, Orvell C, Rafnar B, Norrby E. Two distinct subtypes of human respiratory syncytial virus. J Gen Virol. 1985;66(Pt 10):2111-24. http://dx.doi.org/10.1099/0022-1317-66-10-2111

3. Cane PA. Molecular epidemiology of respiratory syncytial virus. Rev Med Virol. 2001;11(2): 103-16. http://dx.doi. org/10.1002/rmv.305

4. Trento A, Galiano M, Videla C, Carballal G, Garcia-Barreno $B$, Melero JA, et al. Major changes in the $G$ protein of human respiratory syncytial virus isolates introduced by a duplication of 60 nucleotides. J Gen Virol. 2003;84(Pt 11):3115-20. http:// dx.doi.org/10.1099/vir.0.19357-0

5. Peret TC, Hall CB, Schnabel KC, Golub JA, Anderson LJ. Circulation patterns of genetically distinct group $A$ and $B$ strains of human respiratory syncytial virus in a community. Gen Virol. 1998;79(Pt 9):2221-9.

6. Venter M, Madhi SA, Tiemessen CT, Schoub BD. Genetic diversity and molecular epidemiology of respiratory syncytial virus over four consecutive seasons in South Africa: identification of new subgroup $A$ and $B$ genotypes. J Gen Virol. 2001;82(Pt 9):2117-24.

7. Shobugawa Y, Saito R, Sano Y, Zaraket H, Suzuki Y, Kumaki $A$, et al. Emerging genotypes of human respiratory syncytial virus subgroup A among patients in Japan. J Clin Microbiol. 2009;47(8):2475-82. http://dx.doi.org/10.1128/JCM.00115-09

8. Rebuffo-Scheer C, Bose M, He J, Khaja S, Ulatowski M, Beck $E T$, et al. Whole genome sequencing and evolutionary analysis of human respiratory syncytial virus $A$ and $B$ from Milwaukee, WI 1998-2010. PLoS One. 2011;6(10):e25468. http://dx.doi. org/10.1371/journal.pone.0025468

9. Zlateva KT, Lemey P, Vandamme AM, Van Ranst M. Molecular evolution and circulation patterns of human respiratory syncytial virus subgroup a: positively selected sites in the attachment g glycoprotein. J Virol. 2004;78(9):4675-83. http:// dx.doi.org/10.1128/JVI.78.9.4675-4683.2004

10. Botosso VF, Zanotto PM, Ueda M, Arruda E, Gilio AE, Vieira SE, et al. Positive selection results in frequent reversible amino acid replacements in the $\mathrm{G}$ protein gene of human respiratory syncytial virus. PLoS Pathog. 2009;5(1):e1000254. http:// dx.doi.org/10.1371/journal.ppat.1000254

11. Katzov-Eckert H, Botosso VF, Neto EA, Zanotto PM; and the VGND consortium. Phylodynamics and Dispersal of HRSV Entails Its Permanence in the General Population in between Yearly Outbreaks in Children. PLoS One. 2012;7(10):e41953. http://dx.doi.org/10.1371/journal.pone.0041953

12. Zlateva KT, Vijgen L, Dekeersmaeker N, Naranjo C, Van Ranst M. Subgroup prevalence and genotype circulation patterns of human respiratory syncytial virus in Belgium during ten successive epidemic seasons. J Clin Microbiol. 2007;45(9):3022-30. http://dx.doi.org/10.1128/JCM.00339-07

13. van Niekerk $S$, Venter M. Replacement of previously circulating respiratory syncytial virus subtype $B$ strains with the $B A$ genotype in South Africa. J Virol. 2011;85(17):8789-97. http:// dx.doi.org/10.1128/JVI.02623-10

14. Houspie L, Lemey P, Keyaerts E, Reijmen E, Vergote V, Vankeerberghen A, et al. Circulation of HRSV in Belgium: from multiple genotype circulation to prolonged circulation of predominant genotypes. PLoS One. 2013;8(4):e60416. http:// dx.doi.org/10.1371/journal.pone.0060416

15. Kumaria R, Iyer LR, Hibberd ML, Simões EA, Sugrue RJ. Whole genome characterization of non-tissue culture adapted HRSV strains in severely infected children. Virol J. 2011;8:372. http:// dx.doi.org/10.1186/1743-422X-8-372

16. Montieri S, Puzelli S, Ciccozzi M, Calzoletti L, Di Martino A, Milia MG, et al. Amino acid changes in the attachment $G$ glycoprotein of human respiratory syncytial viruses (subgroup A) isolated in Italy over several epidemics (1997-2006). Med Virol. 2007;79(12):1935-42. http://dx.doi.org/10.1002/ jmv.21012
17. Reiche J, Schweiger B. Genetic variability of group A human respiratory syncytial virus strains circulating in Germany from 1998 to 2007. J Clin Microbiol. 2009;47(6):1800-10. http:// dx.doi.org/10.1128/JCM.02286-08

18. Eshaghi A, Duvvuri VR, Lai R, Nadarajah JT, Li A, Patel SN, et al. Genetic variability of human respiratory syncytial virus a strains circulating in Ontario: a novel genotype with a 72 nucleotide G gene duplication. PLoS One. 2012;7(3):e32807. http://dx.doi.org/10.1371/journal.pone.0032807

19. Wertheim JO, Worobey M. Relaxed selection and the evolution of RNA virus mucin-like pathogenicity factors. J Virol. 2009;83(9):4690-4. http://dx.doi.org/10.1128/JVI.02358-08

20. Midulla F, Scagnolari C, Bonci E, Pierangeli A, Antonelli G, De Angelis $D$, et al. Respiratory syncytial virus, human bocavirus and rhinovirus bronchiolitis in infants. Arch Dis Child. 2010;95(1):35-41. http://dx.doi.org/10.1136/adc.2008.153361

21. Pierangeli A, Gentile M, Di Marco P, Pagnotti P, Scagnolari C, Trombetti S, et al. Detection and typing by molecular techniques of respiratory viruses in children hospitalized for acute respiratory infection in Rome, Italy. J Med Virol. 2007;79(4):463-8. http://dx.doi.org/10.1002/jmv.20832

22. Tan L, Lemey P, Houspie L, Viveen MC, Jansen NJ, van Loon AM, et al. Genetic variability among complete human respiratory syncytial virus subgroup A genomes: bridging molecular evolutionary dynamics and epidemiology. PLoS One. 2012;7(12):e51439. http://dx.doi.org/10.1371/journal. pone.0051439

23. Khor CS, Sam IC, Hooi PS, Chan YF. Displacement of predominant respiratory syncytial virus genotypes in Malaysia between 1989 and 2011. Infect Genet Evol. 2013;14:357-60. http://dx.doi.org/10.1016/j.meegid.2012.12.017

24. Posada D. jModelTest: phylogenetic model averaging. Mol Biol Evol. 2008;25(7):1253-6. http://dx.doi.org/10.1093/molbev/ msno83

25. Tamura K, Peterson D, Peterson N, Stecher G, Nei M, Kumar S. MEGA5: molecular evolutionary genetics analysis using maximum likelihood, evolutionary distance, and maximum parsimony methods. Mol Biol Evol. 2011;28(10):2731-9. http:// dx.doi.org/10.1093/molbev/msr121

26. Agoti CN, Mwihuri AG, Sande CJ, Onyango CO, Medley GF, Cane PA, et al. Genetic relatedness of infecting and reinfecting respiratory syncytial virus strains identified in a birth cohort from rural kenya. J Infect Dis. 2012;206(10):1532-41. http:// dx.doi.org/10.1093/infdis/jis570

27. Sande CJ, Mutunga MN, Medley GF, Cane PA, Nokes DJ. Groupand genotype-specific neutralizing antibody responses against respiratory syncytial virus in infants and young children with severe pneumonia. J Infect Dis. 2013;207(3):489-92. http:// dx.doi.org/10.1093/infdis/jis700

28. Yamaguchi M, Sano Y, Dapat IC, Saito R, Suzuki Y, Kumaki A, et al. High frequency of repeated infections due to emerging genotypes of human respiratory syncytial viruses among children during eight successive epidemic seasons in Japan. J Clin Microbiol. 2011;49(3):1034-40. http://dx.doi.org/10.1128/ JCM.02132-10

29. Valley-Omar Z, Muloiwa R, Hu NC, Eley B, Hsiao NY. Novel respiratory syncytial virus subtype $\mathrm{ON}_{1}$ among children, Cape Town, South Africa, 2012. Emerg Infect Dis. 2013;19(4):668-70. http://dx.doi.org/10.3201/eid1904.121465

30. Prifert C, Streng A, Krempl CD, Liese J, Weissbrich B. Novel respiratory syncytial virus $A$ genotype, Germany, 20112012. Emerg Infect Dis. 2013;19(6):1029-30. http://dx.doi. org/10.3201/eid1906.121582

31. Stokes KL, Chi MH, Sakamoto K, Newcomb DC, Currier MG Huckabee MM, et al. Differential pathogenesis of respiratory syncytial virus clinical isolates in BALB/c mice. J Virol. 2011;85(12):5782-93. http://dx.doi.org/10.1128/JVI.01693-10

32. Villenave R, O’Donoghue D, Thavagnanam S, Touzelet 0 , Skibinski G, Heaney LG, et al. Differential cytopathogenesis of respiratory syncytial virus prototypic and clinical isolates in primary pediatric bronchial epithelial cells. Virol J. 2011;8:43. http://dx.doi.org/10.1186/1743-422X-8-43

33. Panayiotou C, Richter J, Koliou M, Kalogirou N, Georgiou E, Christodoulou C. Epidemiology of respiratory syncytial virus in children in Cyprus during three consecutive winter seasons (2010-2013): age distribution, seasonality and association between prevalent genotypes and disease severity. Epidemiol Infect. 2014 Jan 24:1-6. [Epub ahead of print] http://dx.doi. org/10.1017/So950268814000028

34. Meerhoff TJ, Mosnier A, Schellevis F, Paget WJ; EISS RSV Task Group. Progress in the surveillance of respiratory syncytial virus (RSV) in Europe: 2001-2008. Euro Surveill. 2009;14(40): $\mathrm{pii}=19346$. 